\title{
Job satisfaction among Ethiopian nurses: a systematic review
}

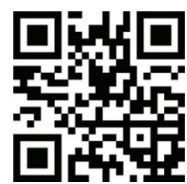

Original article

\author{
Abera Areri Habtamua,b, Alebel Animut ${ }^{\mathrm{a}}$, Deribe Luela \\ ${ }^{a}$ School of Nursing and Midwifery, College of Health Sciences, Addis Ababa University, Addis Ababa 4412, Ethiopia \\ ${ }^{b}$ Eagle college, Addis Ababa 11801, Ethiopia \\ ${ }^{\circ}$ College of Science, Debre Markos University, Debre Markos, Amhara 269, Ethiopia
}

Received: 22 April 2020; Accepted: 11 June 2020; Published: 20 March 2021

\begin{abstract}
Objective: Job satisfaction is a positive emotional feeling in the working environment, and it is an essential tool with which to improve patient safety, nurses' efficiency and performance, quality of care, retention and turnover of nurses, and commitment to the organization and the profession. There are few studies on job satisfaction of nurses in the country. Therefore, this review aims to estimate the pooled prevalence of job satisfaction among Ethiopian nurses using the available studies.

Methods: This systematic review used the Preferred Reporting Items for Systematic Reviews and Meta-Analyses (PRISMA) guideline to synthesize the evidence on the prevalence and associated factors of nurses' job satisfaction. Databases used for searching the included articles from PubMed, Embase, CINHAL, Google Scholar, HINARI, and ScienceDirect. All papers selected for inclusion were subjected to a rigorous appraisal using a standardized critical appraisal checklist (JBI checklist). STATA software (version 11) was used for the analysis, and $95 \%$ confidence intervals were calculated. The Cochrane $Q$ test statistics and ${ }^{2}$ tests were used to assess the heterogeneity prevailing between the studies. Finally, a random effect model was computed to estimate the pooled prevalence of nurses' job satisfaction in the country.

Results: In this review, the data of 1,151 nurses were obtained from six studies. The pooled prevalence of nurses' job satisfaction was found to be $39.53 \%(24.52,54.53)$. The prevalence of job satisfaction in the Central part of Ethiopia was low: $31.12 \%(95 \% \mathrm{Cl} 5.25$, 56.99) compared to the South-Eastern part of Ethiopia's $48.01 \%$ (95\% Cl 36.51, 59.52). The most common predictors identified were salary $(P<0.05)$, the leadership of the organization $(P<0.05)$, and training opportunities $(P<0.05)$.

Conclusions: The pooled prevalence of job satisfaction among nurses was found to be low in comparison with global data. The significant predictors for nurses' job satisfaction are based on the review findings, salary, leadership of organization, and training opportunities.
\end{abstract}

Keywords: $j o b \cdot$ satisfaction $\bullet$ job satisfaction • nurses • Ethiopia

(c) Shanxi Medical Periodical Press.

\section{Introduction}

Job satisfaction refers to a positive emotional feeling that can be obtained from job experiences, and it is one of the individualistic elements of happiness derived from the working environment. ${ }^{1,2}$ Job satisfaction is an essential component of nurses' lives that can impact patient safety, efficiency and performance, quality of care, retention and turnover, and commitment to the organization and the profession. ${ }^{3}$ Moreover, it can determine the productivity and efficacy of human resources. ${ }^{4}$

How to cite this article: Habtamu AA, Animut A, Luel D. Job satisfaction among Ethiopian nurses: a systematic review. Front Nurs. 2021;1:75-82. 
'Improving nurses' working conditions may improve both nurses' and patients' satisfaction as well as the quality of care." A study conducted in Slovenia shows "satisfied employees play a crucial role in an organization's success, so health-care organizations must be aware of the importance of employees' job satisfaction." ${ }^{\prime}$ Our study ascertains that in the USA, leadership attributes can influence the nurses' job satisfaction. ${ }^{7}$

In Pakistan, over half of the nurses were satisfied with their job, and they received an honor from peers, hospital administration, and doctors. Work overload, job rotation, and emotional exhaustion from work were predictors for job satisfaction of nurses. ${ }^{8}$ Job dissatisfaction among nurses was highest in the USA (41\%) followed by Scotland (38\%), England (36\%), Canada $(33 \%)$, and Germany (17\%). Regarding the work climate, when compared with other countries, the nurses in Germany (61\%) reported that they derived greater satisfaction from the opportunities available for career advancement, whereas nurses in the USA (57\%) and Canada $(69 \%)$ felt that they derived greater satisfaction from their salaries. ${ }^{9} \mathrm{~A}$ study in Swiss hospitals indicates supportive leadership, better teamwork, safe residency, and adequate staffs to be positive predictors of nurses' job satisfaction. ${ }^{10}$ A study in South Africa showed benefits and rewards could be key predictors of nurses' job satisfaction. ${ }^{11}$

Nurses play a crucial and important role in hospitals. In the profession of nursing, job satisfaction has supreme importance, since nurses deriving satisfaction from their job will perform better, which ultimately affects the condition of patients. ${ }^{8}$ However, nurses who are not satisfied with their job will involve themselves in disputes and high turnover, and their patients will be dissatisfied. ${ }^{5}$ Nurses are the most undervalued teams among healthcare staff despite the fact that they are working with admitted patients for the whole time during the patients' stay in hospital. Currently, nurses in Ethiopia seem less satisfied, and are leaving their profession and joining non-nursing fields due to inadequate salary, shift schedules, and community perceptions of the nursing profession. ${ }^{4}$

Studies carried out in relation to the satisfaction leve of nurses toward their profession in Ethiopia show $30.7 \%$ in West Show Zone of Oromia, ${ }^{12} 47.5 \%$ in Sidama Zone of the Southern region of Ethiopia, ${ }^{13} 54.2 \%$ in East Gojjam Zone of Amhara region, ${ }^{14} 37.9 \%$ in Harari region, ${ }^{15}$ $50.6 \%$ in Addis Ababa region, ${ }^{16}$ and $58.13 \%$ in Jimma University Specialized Teaching Hospital. ${ }^{4}$ However, others studies have reported different level of nurses' satisfaction toward their job such as in Jimma Zone public hospitals where there is about $34.5 \%$ (moderate), $33.5 \%$ (low), and $32 \%$ (high) level of job satisfaction, ${ }^{4}$ and in Jimma University Specialized Teaching Hospital, overall mean job satisfaction by nurses was 2.21 (SD, 0.52 ), which is a low score out of 5 . $^{1}$

In a different part of the country, there were studies done, but no national study that estimated pooled prevalence of job satisfaction in Ethiopia. The prevalence from these small studies was characterized by significant variability, and the finding from these studies was inconclusive in prevalence..$^{4,12-16}$ Therefore, this study aims to estimate the prevalence of job satisfaction among nurses countrywide by using the results from these articles. Nurses' job satisfaction has been declining in Ethiopia; this review is designed to generate evidence on the current prevalence of job satisfaction among nurses. The study findings help policymakers in the designing of appropriate interventions to improve nurses' job satisfaction and thereby improve the healthcare system of the country.

\section{Methods}

\subsection{Inclusion criteria}

Studies that included job satisfaction of nurses regardless of race, region of residence, level of education, experience differences, or other characteristics of satisfaction were included. The review included studies conducted in Ethiopia and published and unpublished English language articles in peer-reviewed journals. All original observational studies that report the prevalence of nurses' job satisfaction and their associated factors with job satisfaction having a response rate of $\geq 80 \%$ were included. The review excluded those articles that were not capable of being fully accessed even after we contacted the primary author at least twice through email to obtain full access. Besides, those articles without a clear report on nurses' job satisfaction were excluded.

\subsection{Searching strategies}

The search strategy applied a three-step process to identify published papers. The first step of the search was limited to PubMed and CINAHL to identify keywords and terms contained in the title and abstract, and the index terms used to describe articles. The second step, search, was conducted using pre-identified keywords and index words across six databases: PubMed, Google Scholar, CINAHL, HINARI, ScienceDirect, and EMBASE. Initial keywords were "Job", "satisfaction," "Nurses," "Ethiopia nurses," "prevalence," and "job satisfaction of nurses." The search 
terms were used separately and in combination using Boolean operators "OR" or "AND." Finally, in the third step, the reference lists of all identified reports and articles were searched for additional studies. The search was conducted from August 21 to September 8,2018 . Further, the review included all papers published till the end of 2017.

\subsection{Outcome measurement}

The primary outcome of the exercise mentioned above is nurses' job satisfaction. The prevalence was calculated by dividing the number of nurses satisfied with the total number of nurses included in the study. The secondary outcome of the study was to determine the associated factors for job satisfaction among nurses.

\subsection{Data abstraction}

A standardized data extraction format adapted from the Joanna Briggs Institute Meta-Analysis of Statistics Assessment and Review Instruments (JBI-MAStARI) was used. The data extraction was done by two researchers (H.A., A.A.) using the JBI review format. ${ }^{17}$ Any disagreements that arose between the reviewers were resolved through discussions. The disagreement between the two reviewers was resolved by taking the mean score.

\subsection{Quality assessment}

A cross-sectional study quality assessment tool was used to assess the quality of each study. ${ }^{18}$ Two reviewers independently appraised the quality of each study using the tool. Disagreements between the two reviewers were resolved by taking their mean scores. Finally, the research with a scale of $\geq 6$ out of 10 scales was considered as high quality.

\subsection{Statistical analysis}

Data were extracted in Microsoft Excel format, and then they were imported into STATA 11 for further analysis. Association effect sizes and their 95\% confidence intervals were calculated for analysis. Where statistical pooling was not possible, the findings were presented in narrative form. The standard error for each study was calculated using the binomial distribution formula. Heterogeneity among reported prevalence was assessed using the Cochrane $Q$ and $l^{2}$ tests. ${ }^{19}$ The result showed that there is significant heterogeneity among studies $\left(R^{2}=96.8 \%, P<0.001\right)$. In the forest plot, the size of each box indicated the weight of the study, whereas each crossed line refers to a $95 \%$ confidence interval. For the second outcome logs, the odds ratio was used to determine the associated factors to job satisfaction among nurses in Ethiopia. Publication bias was assessed using the Egger's and Begg's tests.

\section{Results}

In all, 543 articles were retrieved related to job satisfaction of nurses in Ethiopian hospitals through PubMed, CINHAL, Embase, Google Scholar, ScienceDirect, Hinari, and other sources. Of these, 163 were duplicates. Again, 387 papers were excluded because their titles were found to be irrelevant among the remaining 410 papers. The remaining 23 full articles were screened based on the pre-set criteria, and 17 were excluded due to the outcome of interest. Finally, only six papers were included in the systematic review (Figure 1).

\subsection{Characteristics of the studies}

The studies were published from 2013 to 2017 . The current systematic review included 1,151 nurses. All studies were cross-sectional studies. The highest prevalence of nurses' job satisfaction was reported from a study done in Jimma University Specialized Teaching Hospital to be $58.13 \%$ in Oromia regional state. ${ }^{4}$ On the other hand, the lowest prevalence $(30.7 \%)$ was reported from a study done in West Showa Zone, Oromia regional state. ${ }^{12}$ In this meta-analysis, five regions of the country were represented: one study from the Amhara region, ${ }^{14}$ one from Addis Ababa, ${ }^{16}$ two from the Oromia region, ${ }^{4,12}$ one from the SNNP region ${ }^{13}$, and one from the Harari region. ${ }^{15}$ The response rate of each original study ranged from $87 \%$ to $100 \%$, and almost all studies had an acceptable response rate (Table 1 ).

\subsection{Heterogeneity and publication bias}

The included articles exhibited high heterogeneity according to the Cochrane $Q$ test $(Q$ test $P=0.001)$ and $I^{2}$ test $\left(I^{2}=96.8 \%\right)$; this fact is indicative of using a random-effects model. Also, we performed subgroup analysis based on the geographical settings where the studies were conducted (the Central part of Ethiopia and Southeast part of Ethiopia). However, the Egger's weighted regression statistics $(P=0.10)$ and the Begg's rank correlation statistics $(P=0.44)$ indicated no evidence of publication bias. Therefore, the review included heterogonous articles, these are solved using the random-effects model, and there is no indication of bias in the included papers. 




Figure 1. Flowchart of the study selection and inclusion process.

\begin{tabular}{lllcccc}
\hline $\begin{array}{l}\text { Location of study } \\
\text { area }\end{array}$ & Study place & Authors name & $\begin{array}{c}\text { Publication } \\
\text { Year }\end{array}$ & $\begin{array}{c}\text { Response } \\
\text { rate (\%) }\end{array}$ & $\begin{array}{c}\text { Sample size } \\
\text { Prevalence } \\
(95 \% \mathrm{Cl})\end{array}$ \\
\hline \hline $\begin{array}{l}\text { Central part of } \\
\text { Ethiopia }\end{array}$ & West Shoa Zone hospitals & Mulugeta et al. ${ }^{12}$ & 2015 & 100 & 166 & $30.70(23.68,37.72)$ \\
& East Gojam Zone hospitals & Haile et al. ${ }^{14}$ & 2017 & 98.3 & 178 & $54.20(46.88 .61 .52)$ \\
& Addis Ababa & Sinidu et al. ${ }^{16}$ & 2014 & 100 & 70 & $8.58(2.02,15.14)$ \\
$\begin{array}{l}\text { South-Eastern part } \\
\text { of Ethiopia }\end{array}$ & Sidama Zone hospitals & Agezegn et al. ${ }^{13}$ & 2014 & 87 & 542 & $47.50(41.21,53.29)$ \\
& Harari region hospitals & Ayele et al. ${ }^{15}$ & 2015 & 100 & 182 & $37.90(30.85,44.95)$ \\
& Jimma University & Semachew et al. ${ }^{4}$ & 2017 & 92.7 & 316 & $58.13(52.69,63.57)$ \\
& $\begin{array}{l}\text { Specialized Teaching } \\
\text { Hospital }\end{array}$ & & & & & \\
& Total nurses included in the study & & & 1,151 & $39.53(24.52,54.53)$ \\
\hline
\end{tabular}

Table 1. Descriptive summary of six studies included in the meta-analysis of the prevalence of nurses' job satisfaction in Ethiopia

\subsection{Meta-analysis}

The analysis of six studies, according to the DerSimonian-Laird random effects model, revealed that the pooled prevalence of job satisfaction among the Ethiopian nurses was $39.53 \%$ (95\% Cl: $24.52 \%, 54.53 \%)$ (Figure 2). Subgroup analyses showed that the prevalence of job satisfaction in the Central part of Ethiopia was $31.12 \%(95 \% \mathrm{Cl}: 5.25,56.99)$, and that of SouthEastern Ethiopian nurses' was 48.01\% (95\% Cl: 36.51 , 59.52) (Figure 2).

\subsection{Factors associated with job satisfaction among Ethiopian nurses}

As indicated in Table 2, four studies were included in a systemic review to narrate the factors influencing job satisfaction of nurses in Ethiopia. The common factors which were affecting job satisfaction were identified, analyzed, and presented in thematic ways. Therefore, the relevant factors included leadership relationship with nurses, nurses' autonomy, work environment, group cohesion among nurses, training, and presence of work 


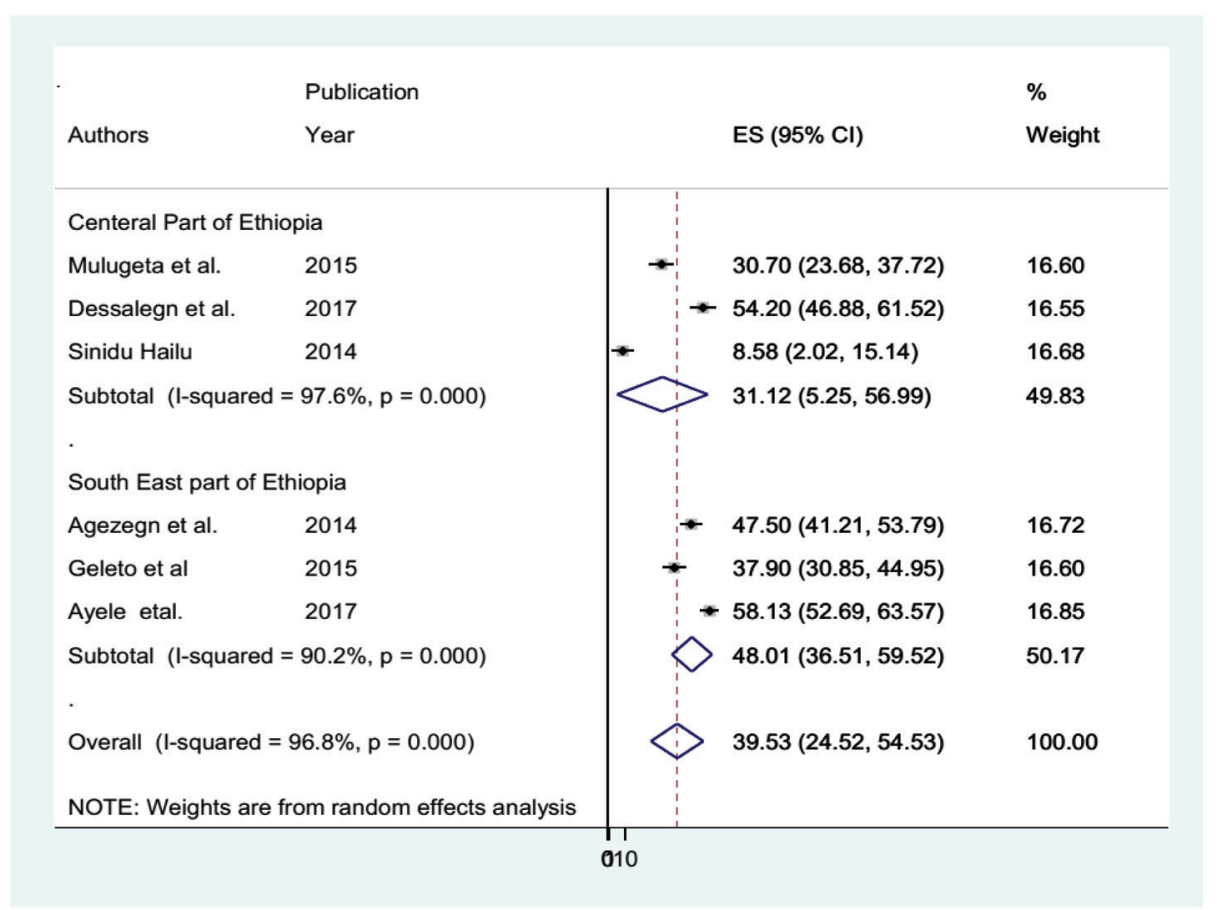

Figure 2. Forest plot of the six studies that quantitatively assessed prevalence of nurses' job satisfaction in Ethiopia, 2017.

employment opportunity ${ }^{13,14,16}$; the presence of opportunities for promotion and recognition at the workplace ${ }^{13,14}$ were positive predictors for job satisfaction of nurses working in Ethiopian hospitals. Moreover, the working environment, mutual understanding among nurses, and workload were positive predictors for job satisfaction of nurses. . $^{43,14,16}$

\section{Discussion}

Determining job satisfaction and associated factors among Ethiopian nurses has a great contribution to policymakers and program planners because nurses are the cornerstone of patient care in the healthcare system. Despite this, the pooled prevalence of job satisfaction among nurses at the national level has not yet been estimated. Therefore, the main aim of this systematic review and meta-analysis was to estimate the pooled prevalence of job satisfaction among Ethiopian nurses and the factors associated with it.

According to Mulugeta et al. ${ }^{12}(30.70 \%)$, Haile et al. ${ }^{14}$ (54.20\%), Sinidu et al. (8.58\%), ${ }^{16}$ Agezegn et al. ${ }^{13}(47.5 \%)$, Ayele et $\mathrm{al}^{15}(37.9 \%)$, and Semachew et $\mathrm{al}^{4}{ }^{4}$ (58.13\%), the prevalence of job satisfaction of nurses in different parts of Ethiopia was in the range $8.58 \%-58.13 \%$ from
2014 to 2017 . This meta-analysis summarized all these findings and showed the prevalence of nurses' job satisfaction was $39.53 \%$ in the public hospitals of Ethiopia.

The finding of this study revealed that the pooled prevalence of job satisfaction among Ethiopian nurses was $39.53 \%$ (95\% Cl: $24.52 \%, 54.53 \%$ ), which is lower when compared with the findings from Pakistan, where more than half of the nurses were satisfied with their job $(51.5 \%){ }^{8}$ However, the finding is in line with literature reported from the USA $(41 \%)$ and Scotland $(38 \%){ }^{8}$ In contrast, it is higher than the level of job satisfaction which is found in the literature reported from England (36\%), Canada (33\%), and Germany (17\%). ${ }^{9}$ The possible explanation for the difference could be the time gap, which included recent studies; also, the range of papers included in this study was very limited; there were no intensive studies made when compared to those studies.

Subgroup analysis based on the location of the study showed a lower prevalence of job satisfaction among nurses in the Central part of Ethiopia (31.12\%) compared to the South-Eastern part of Ethiopia (48.01\%). The difference in this prevalence between the two areas of Ethiopia could be related to the cost of living, which is high in urban areas, the difference in patient load and staff development opportunities, and the difference in the hospitals. 


\begin{tabular}{|c|c|c|}
\hline $\begin{array}{l}\text { Study area, Author } \\
\text { reference }\end{array}$ & Key findings & Comments \\
\hline \multirow[t]{4}{*}{$\begin{array}{l}\text { Sidama Zone public } \\
\text { hospitals }^{13}\end{array}$} & $\begin{array}{l}\text { Nurses with service between } 5 \text { and } 10 \text { years }(78 \% \text { less likely } \\
\text { to be satisfied }(\mathrm{OR}=0.22(95 \% \mathrm{Cl}: 0.06,0.96)))\end{array}$ & $\begin{array}{l}\text { As experience increases, job satisfaction } \\
\text { might decrease }\end{array}$ \\
\hline & $\begin{array}{l}\text { Leadership relation in the organization }(\mathrm{OR}=23.30(95 \% \mathrm{Cl} \text { : } \\
5.02,108.22))\end{array}$ & Positive predictor of job satisfaction \\
\hline & $\begin{array}{l}\text { Work environment and group cohesion }(\mathrm{OR}=26.63(95 \% \\
\mathrm{Cl}: 4.26,16.20)) \text { and } 75 \% \text { less likely to leave their work } \\
(\mathrm{OR}=0.25(95 \% \mathrm{Cl}: 0.12,0.51))\end{array}$ & \\
\hline & $\begin{array}{l}\text { Recognition at work, employment opportunity, presence of } \\
\text { training, autonomy, and promotion were also predictors of } \\
\text { job satisfaction }(P<0.05)\end{array}$ & $\begin{array}{l}\text { Over half of the nurses are satisfied with the } \\
\text { leadership (57\%), work environment (54.5\%), and } \\
\text { recognition at work (50.4\%) }\end{array}$ \\
\hline East Gojjam hospitals ${ }^{14}$ & $\begin{array}{l}\text { Promotion, salary, leadership (supervision), relationship with } \\
\text { co-workers, work environment, communication, and rewards } \\
\text { were } \\
\text { found to be predictors }(P<0.05)\end{array}$ & $\begin{array}{l}\text { A moderate level of satisfaction was observed in } \\
\text { this study }\end{array}$ \\
\hline Addis Ababa hospitals ${ }^{16}$ & $\begin{array}{l}\text { Predictor variables were: } \\
\text { - relationship among staff }(P<0.001) \\
\text { - training opportunity }(P<0.04) \\
\text { - autonomy ( } 50 \% \text { of nurses were satisfied) } \\
\text { - } 91.43 \% \text { dissatisfied because of salary }\end{array}$ & $\begin{array}{l}\text { Most nurses were not satisfied in this study and the } \\
\text { reasons identified were bad working environment, } \\
\text { poor salary, transport problem, administrative } \\
\text { problems, and lack of training and benefits }\end{array}$ \\
\hline $\begin{array}{l}\text { Jimma University } \\
\text { Specialized Teaching } \\
\text { Hospital }^{4}\end{array}$ & $\begin{array}{l}\text { Mutual understanding at work, working environment, and } \\
\text { professional commitment were positive predictors, whereas } \\
\text { workload was a negative predictor }(P<0.05) \text {. } \\
\text { Nurses were least satisfied with rewards and professional } \\
\text { opportunities. } \\
\text { Leadership is not satisfying the nurses. } \\
\text { Salary was least satisfying ( } 59.8 \%) \text {. } \\
\text { Education level was a negative predictor }\end{array}$ & $\begin{array}{l}\text { Mutual understanding at work brings a sense of } \\
\text { recognition and feeling of respect among nurses, } \\
\text { which can lead to job satisfaction }\end{array}$ \\
\hline
\end{tabular}

Table 2. Factors affecting nurses' job satisfaction in each study of Ethiopia, 2017.

In this study, we also assessed other factors that are associated with job satisfaction. Accordingly, the review indicates that salary was found to be an important positive and negative predictor of job satisfaction of nurses in Ethiopia. ${ }^{4,14-16}$ An adequate salary motivates nurses to stay in their nursing job. If nurses are not satisfied with their current job, they may start looking for additional opportunities, which could affect their stability and increase their chance of turnover. This finding is in line with the findings from the USA, Canada, England, Scotland, and Germany. ${ }^{9}$ Regarding the work climate, the nurses in Germany $(61 \%)$ reported that they were more satisfied with their opportunities. ${ }^{9}$ This meta-analysis and the systemic review indicate that the leadership of the organization is also a factor $(P<0.05)$ that could affect job satisfaction of nurses in almost all of the studies included in the articles published on Ethiopian nurses. ${ }^{4,13,14}$ The relationship between the nurses and their supervisor in the hospital environment directly or indirectly influences nurses' job satisfaction. A leader who encourages and empowers nurses for their effort could enhance job satisfaction but a leader who lacks these qualities may end up with dissatisfying the nurses working under him/ her. The finding is in line with a study conducted in the USA Pediatrics hospital. ${ }^{7}$ This meta-analysis and the systemic review found that training opportunities in all reviewed papers expect one seemed to be an affecting variable for job satisfaction. ${ }^{13-16}$ Training has a direct effect on nurses' job competency. Therefore, those who got the opportunity and improved their skills could better love their job and be satisfied with what they did on daily basis.

The findings from Jimma University Specialized Teaching Hospital, ${ }^{4}$ East Gojjam hospitals, ${ }^{14}$ and Sidama Zone Ppublic hospitals ${ }^{13}$ were in line with the findings of the Swiss study where supportive leaderships, better teamwork, safe residency, and adequate staffs were positive predictors of nurses' job satisfaction. ${ }^{10}$ Study findings from Jimma University Specialized Teaching Hospital ${ }^{4}$ and East Gojjam hospitals ${ }^{14}$ found that reward is a significant predictor of job satisfaction, which is in line with the conclusions reached in a study from South Africa. ${ }^{11}$ Therefore, the evidence implies that enhancing job satisfaction of nurses depends on the full effort of the stakeholders; the sources of this effort should ideally include hospitals, association, policy makers, health bureaus, and nurses' leaders. 


\section{Conclusions}

The pooled prevalence of nurses' job satisfaction in Ethiopia was found to be low as compared to the global findings of a similar study. Nurses who lived in the Central part of Ethiopia were less satisfied as compared to the nurses in the South-Eastern part of Ethiopia. Salary, benefits, rewards, the leadership of the organization, and the training opportunities were the significant factors affecting nurses' job satisfaction. Therefore, healthcare organizations such as hospital management and regional and federal bureaus should focus on increasing job satisfaction of nurses, since they are the core of the healthcare delivery system of hospitals, by working to improve the components of job satisfaction and also the service quality of the health institutions. Moreover, a special emphasis should be given for nurses in improving their working environments.

\section{Limitation}

The primary limitation of this study was that all studies included in this review were cross-sectional and, therefore, the outcome variable might be affected by other

\section{References}

1. Negussie N. Job satisfaction of nurses in Jimma University Specialized Teaching Hospital, Ethiopia. $J$ Egypt Public Health Assoc. 2016;91:15-19.

2. Negussie N, Kaur G. The effect of job demand-control-social support model on nurses' job satisfaction in specialized teaching hospitals, Ethiopia. Ethiop J Health Sci. 2016;26:311-320.

3. Murrells T, Robinson S, Griffiths P. Job satisfaction trends during nurses' early career. BMC Nurs. 2008;7:7.

4. Semachew A, Belachew T, Tesfaye T, Adinew YM. Predictors of job satisfaction among nurses working in Ethiopian public hospitals, 2014: institutionbased cross-sectional study. Hum Resour Health. 2017;15:31.

5. McHugh MD, Kutney-Lee A, Cimiotti JP, Sloane DM, Aiken LH. Nurses' widespread job dissatisfaction, burnout, and frustration with benefits signal problems for patient care. Health Aff (Millwood). 2011;30:202-210.

6. Mateja L, Brigita SS. Job satisfaction of nurses and identifying factors of job satisfaction in Slovenian Hospitals. Croat Med J. 2012;53:263-270. confounding variables. The limited sample size could affect the estimated value. Moreover, this meta-analysis represented studies reported from only five regions of the country.

\section{Acknowledgment}

H.A.: conception of the research protocol, study design, literature review, data extraction, data analysis, interpretation, and drafting of the manuscript. A.A. and L.D.: data analysis and reviewing the manuscript, involvement in data extraction, and quality assessment. All authors have read and approved the manuscript.

\section{Ethical approval}

Ethical issues are not involved in this paper.

\section{Conflicts of interest}

All contributing authors declare that no conflicts of interest exist.

7. Andrews DR, Richard DCS, Robinson P, Celano P, Hallaron J. The influence of staff nurse perception of leadership style on satisfaction with leadership: a cross-sectional survey of paediatric nurses. Int $J$ Nurs Stud. 2012;49:1103-1111.

8. Irum SD, Muhammad AH. Factors influencing job satisfaction of nurses in public hospitals. Sci Int (Lahore). 2015;27:1761-1765.

9. Lu H, Barriball KL, Zhang X, While AE. Job satisfaction among hospital nurses revisited: a systematic review. Int J Nurs Stud. 2012;49:1017-1038.

10. Schwendimann R, Dhaini S, Ausserhofer D, Engberg $S$, Zúñiga F. Factors associated with high job satisfaction among care workers in Swiss nursing homes-a cross sectional survey study. BMC Nurs. 2016;15:37.

11. Dhurup M. Van Zyl Y, Mokhathi MS. Factors influencing job satisfaction and its relationship on career development among nursing staff within a public hospital in South Africa. Mediterr J Soc Sci. 2014;5:79-86.

12. Mulugeta MM, Ayele GB. Factors associated to job satisfaction among healthcare workers at public 
hospitals of West Shoa Zone, Oromia Regional State, Ethiopia: a cross sectional study. Sci J Public Health. 2015;3:161-167.

13. Agezegn A, Tefera B, Ebrahim Y. Factors influencing job satisfaction and anticipated turnover among nurses in Sidama Zone Public Health Facilities, South Ethiopia. Nurs Res Pract. 2014;2014: 909768.

14. Haile D, Gualu T, Zeleke H, Dessalegn B. Job satisfaction and associated factors among nurses in East Gojjam Zone Public Hospitals Northwest Ethiopia. J Nurs Care. 2017;6:398.

15. Ayele G, Negga B, Gudina EA, Yadeta D. Job satisfaction and associated factors among health care providers at public health institutions in Harari region, Eastern Ethiopia: a cross-sectional study. BMC Res Notes. 2015;8:394.
16. Sinidu $\mathrm{H}$. A study on assessment of job satisfaction among nurses working in an emergency department in three hospitals of Addis Ababa. 2014. Unpublished maters theses.

17. The JBI. Joanna Briggs Institute Reviewers' Manual; 2008.

18. Newcastle-Ottawa Scale customized for cross-sectional studies. https://static-content.springer.com/ esm/.../12889_2012_5111_MOESM3_ESM.doc.

19. Rücker et al. Undue reliance on I 2 in assessing heterogeneity may mislead. BMC Med Res Methodol. 2008;8:79.

20. Liberati A, Altman DG, Tetzlaff J, et al. The PRISMA statement for reporting systematic reviews and meta-analyses of studies that evaluate health care interventions: explanation and elaboration. J Clin Epidemiol. 2009;62:e1-e34. 